\title{
The Virtual Discourse in On-line Newspapers
}

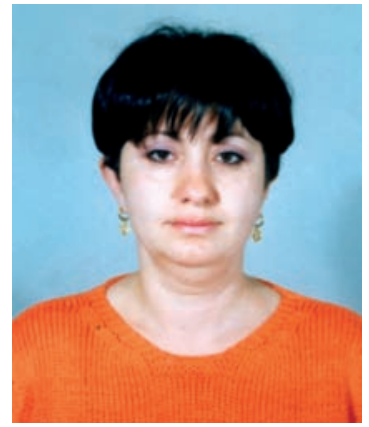

Lusine Fljyan

$\mathrm{T}$ he Internet's recent emergence into our reality has modified, influenced and even changed different aspects of human life. The process of a technology coming to acceptance involves more than just creating better hardware and software. The development of electronic or on-line communication has created a new type of a discourse virtual, which exists both in spoken and written forms and may be treated as a hybrid of other traditional discourses. "Virtual reality is now widely recognized as a credible technology, and has a tangible discourse".

Today the WWW (World Wide Web) comprises a large number of processes, communities, styles and genres as everything may be on-lined and transmitted via the global net. Language, Literature, Commerce, Arts may be digitalized and introduced electronically to an auditorium of huge sizes and in a large spectrum of forms. In "Writing Space: The Computer, Hypertext, and the History of Writing", Jay David Bolter says: "We have begun by using word processors and electronic photocomposition to improve the production of printed books and other documents. Yet it is already becoming clear that the computer provides a new writing surface that needs conventions different from those of the printed page." "True electronic writing," he continues, "is not limited to verbal text: the writeable elements may be words, images, sounds, or even actions that the computer is directed to perform."

The term "virtual reality" is particularly powerful, because it can attach to a broad range of meanings. It developed from fiction in 1984 to a rich discourse and a marketed technology by 1992. Specialists of virtual reality often observe that it seemed to appear independently in several places at once and it is hard to identify one origin. The virtual discourse that is formed within the cyberspace has colonized other discourses for a specific on-line community. To construct a new type of electronic communication, virtual discourse and virtual reality proponents had to establish a shared terminology and set of assumptions and they did it by incorporating and adapting the language of other discourses. Michel Foucalt used the term "colonization" to mean "the coming to dominance of certain ways of viewing the world"3, and this has clearly happened with virtual reality. Virtual reality is a computer-based technology but as a discourse it has attempted to colonize a range of older, traditionally non-computer based discourses: among them design, art, entertainment, communications and philosophy. It claims to have an "enabling technology" which can do old things better. This process involves retroping (changing the meanings associated with) both the technology and the traditional discourses. 
The electronic communication consists of the following genres: e-mail, chat, online advertisements, on-line literature, scientific articles, videoconferences, distant education, on-line mass media, which involves electronic newspapers, journals, virtual newsstands, radio broadcasts and so on.

The present article aims to describe and examine the virtual discourse in the genre of on-line newspapers. A genre-oriented analysis is particularly useful because it encourages a focus on the medium within which the discourse is embodied.

What is an on-line newspaper?

We define it as a new digitalized technology that introduces different contents of mass information in a hypertextual, non-linear form in the World Wide Web. Any on-line newspaper is global, as potentially all the world may become its reader. Even local virtual newspapers may have a larger auditorium than such global printed publications as Tribune, The Guardian, Financial Times and so on. The auditorium of virtual newspapers is not restricted by place and time, and the new reading structures are coined due to the technical opportunities of the Internet.

What are the basic features and characteristics of virtual newspapers that are common with printed ones?

First of all in both of them the articles are written by real authors - journalists, both variants have their editorial boards that are responsible for the quality of the information introduced in them. In both of them the urgent events of the day are introduced on the first page. Both types consist of various sections according to their main interests. In printed as well as in virtual newspapers the articles may have one or a collective author. ${ }^{4}$ Both the on-line and printed newspapers serve to perform the main two functions of the style: the informative and evaluative, and, hence, in both of them the communicative purposes are to introduce information and to make some influence on the reader.

After defining the similarities of printed and on-line newspapers, we can take our analysis a step further and provide a more detailed description of electronic newspapers. Virtual reality or cyberspace has created a number of advantages of on-line newspapers over their printed counterparts.

- $\quad$ "The article is completing only when the described event is completed. The articles are written in the way so that the last phrase might be added." 5

- The hypertextual character allows searching different materials, finding references and links, and in this sense the process of reading an on-line newspaper is becoming more comprehensive, more profound and varied.

- $\quad$ Virtual newspapers have greater promptitude. They very often overtake printed newspapers and even TV media in the speed of the appearance of its materials.

- The language of on-line newspapers has also its specific rules that should meet the main requirements of on-line communication. The abstracts should be short, and the sentences even shorter. It spares not only space on the web page but also the efforts of the reader to percept the information. The availability of blank space between the abstracts also facilitates the perception. The following article is from "Washington Monthly Online", written by Kevin Drum on November, 30, 2005 : 
TAXING CAPITAL....Max Sawicky ripped off his blogging cape today and adopted the guise of mild mannered serious economist in order to hold. Very quickly, though, the debate turned to the subject of capital gains taxes - specifically whether Max was willing to raise his hand and say: "I want to in essence double the real rate of taxation on capital income. I don't think the growth rate will fall." Here's how Tyler put it:

Max, are you willing to raise your hand and say: "I want to in essence double the real rate of taxation on capital income. I don't think the growth rate will fall?"'

Sadly, the results were unedifying. I demand a rematch.

Basically, I'm on Max's side: I think taxation of capital should be at roughly the same level as taxation of labor income. However, I believe this mostly for reasons of social justice, and it would certainly be handy to have some rigorous economic evidence to back up my noneconomic instincts on this matter. Something juicy and simple for winning lunchtime debates with conservative friends would be best. Unfortunately, Max punts, saying only, "As you know, empirical research seldom settles arguments."

Tyler then accuses of Max of obscurantism and asserts without evidence that "I am asking you to believe that low rates of capital taxation are good for an economy; this accords with most empirics and with most theory."

Perhaps so. But on a question this messy I have little faith in theory. I'd like to hear more about those empirics. Max makes the point that U.S. tax rates on capital are higher than in most countries, and yet our economy is one of the best performing in the world. What's more, we've had higher rates in the past, and have had booming economies regardless. These are good points.

And yet, surely there is some serious comparative research on this matter? Perhaps a consensus within the economics profession? Or not? Inquiring minds want to know.

- The relations between authors and readers in virtual newspapers may be both synchronous and asynchronous, while in ordinary newspapers only asynchronous relations are possible. In on-line newspapers the readers may become interactants and participate in discussions and forums introduced after the article. The active participation and interaction of readers is possible in printed newspapers too. They may write letters to the editorials' office or phone them for expressing their ideas, views, agreements and objections on different issues discussed in them. In the guestbooks that are part and parcels of electronic newspapers the readers are becoming interactants. They may react immediately after reading the article. If the readers of printed newspapers should necessarily introduce themselves in their letters or calls, in virtual guestbooks the readers may hide their names, may act anonymously or using their first names only, or nicknames. The readers' messages can be represented with errors, omissions, changes of plan, hesitations, which are peculiar to spoken communication. The guestbooks are "the hot lines" of on-line newspapers through which the readers are becoming co-authors of the articles, reports and announcements. Hence, in electronic newspapers the readers are becoming not only the objects, but also the subjects of cybercommunication. Below are some of the comments made by readers on the article "Taxing Capital": 
Posted by: on November 30, 2005 at 11:31 PM

(http://www.washingtonmonthly.com/archives/individual/2005_11/007670.php\#765091)

Every time the subject of taxes comes up, the looney Right starts barking about how lower is always better, despite the fact that we have had several periods in history when raising taxes was the right thing to do, and was done, and everyone went home a winner.

It's just a religious argument with these people - to that extent, it is actually true that "empirical research seldom settles arguments."

Posted by: on November 30, 2005 at 11:41 PM

(http://www.washingtonmonthly.com/archives/individual/2005_11/007670.php\#765096)

If you don't think that government does any good, you obviously won't like taxes.

I don't care if capital gains are taxed specifically - there may be reasons why that might not be the best plan. All I care about is that enough taxes are levied for the government to do a full-assed job and that the taxes are levied in as progressive a manner as possible. If that means taxing a stock dividend, fine. If it means taxing a filet mignon or an inheritance or a juicy real-estate sael, fine. fine. fine.

1) adequacy: if government needs go up, so should taxes.

2) progressivity: self explanatory.

Anything else is open for debate.

Posted by: on December 1, 2005 at 12:01 AM

(http://www.washingtonmonthly.com/archives/individual/2005_11/007670.php\#765115)

It doesn't really matter. The market (like magic) will factor everything in.

Seriously. If you raise taxes on capital income, and change nothing else, you lower the real rate of return on capital investments. Such changes don't occur in a vacuum, however. Other factors, such as interest rates, prices, the inflation rate, etc. (the relationships between these factors aren't as fixed or predictable as we'd like to believe), will adjust accordingly to compensate. The macroeconomy (i.e. "growth") will continue as it would have regardless. Investors will always find the best available real rate of return, whatever it is, wherever it is.

As has been shown empirically throughout history, tax rates don't determine the rate of growth in the macroeconomy (low rates didn't stop low growth during the Hoover administration, or during the two Bush admins; high rates didn't stop growth during the 1960s). Tax rates do, however, determine who pockets the profits. Low capital income tax rates are, in effect, a government handout to the investor class.

Posted by: on December 1, 2005 at 12:01 AM (http://www.washingtonmonthly.com/archives/individual/2005_11/007670.php\#765116)

Looks to me like capital is plenty cheap already, given today's high valuations and low interest rates. Bring on the taxes!

Posted by: on December 1, 2005 at 12:03 AM

(http://www.washingtonmonthly.com/archives/individual/2005_11/007670.php\#765118)

Don't you folks at Washington Monthly know any real economists you can 
interview? I mean, we here in the comments can opine and dissect theories and anecdotal evidence until the cows come home, but for this sort of thing, you really should just use your clout to consult the experts.

Posted by: on December 1, 2005 at 12:08 AM

(http://www.washingtonmonthly.com/archives/individual/2005_11/007670.php\#765126)

There's a difference between taxing capital, and taxing capital gains. I'm pretty sure you are talking about the latter, but please be more precice in your terminology, Kevin.

I believe that taxing capital (i.e. taxing wealth rather than income) was considered in the UK after WWII but was never implemented.

Posted by: on December 1, 2005 at 12:09 AM

(http://www.washingtonmonthly.com/archives/individual/2005_11/007670.php\#765128)

When you say you want them to be equal? Do you mean the top tax bracket or somewhere in the middle?

Posted by: on December 1, 2005 at 12:40 AM

(http://www.washingtonmonthly.com/archives/individual/2005_11/007670.php\#765141)

Inflation is also a tax on savings, so don't forget to factor that in.

Inflation is not a tax, OK? Inflation is an organic component of any monetary system. A tax is an instrument of funding government activity. Oi.

Posted by: on December 1, 2005 at 12:41 AM

(http://www.washingtonmonthly.com/archives/individual/2005_11/007670.php\#765143)

Capital is in fact taxed very widely. In almost all states and localities it takes the form of real estate taxes. Some states also have personal property taxes (like car registration rates in MA, based I believe on the value of the car). It just isn't taxed by the feds.

Armchair economist is right about investment decisions being made in a larger context, and about cap-gains taxes mostly determining where profits go. Apropos of this, I'm old enough to remember the school of thought that said that manufacturing investment actually benefits from mild inflation because it improves prospects of nominal profit growth. But that's not orthodoxy at the Fed these days.

Unfortunately, Max is also right that empirical research doesn't settle arguments. Exhibit A is Cowen's pleading with Max to "believe."

Posted by: on December 1, 2005 at 12:43 AM

(http://www.washingtonmonthly.com/archives/individual/2005_11/007670.php\#765145)

As has been shown empirically throughout history, tax rates don't determine the rate of growth in the macroeconomy... Tax rates do, however, determine who pockets the profits.

Clear and succinct. 
Posted by: on December 1, 2005 at 12:44 AM

(http://www.washingtonmonthly.com/archives/individual/2005_11/007670.php\#765146)

When you say you want them to be equal? Do you mean the top tax bracket or somewhere in the middle?

Why can't "equal" just mean "equal", as in "all income is treated alike, whether from capital or labor". Sure, there are measurement issues, but there are measurement issues with income, anyway.

Posted by: on December 1, 2005 at 12:46 AM http://www.washingtonmonthly.com/archives/individual/2005_11/007670.php\#765147

History serves as one existence proof. In the 50's and 60's, we had much higher tax rates on capital gains and enjoyed greater economic growth and job creation than we do today,

As it is well seen from the comments, in virtual communication there is less pressure for readers to conform to the norms of the language. The device that transmits the communication blurs distinction between writing and speech. In total 98 readers took part in the discussion of this article, expressing different viewpoints on the rate of taxation on capital income in the USA. For a local newspaper just this one article has picked up a rather large auditorium of active participants. What are the advantages of such an exchange of opinions? We can say that readers are more socially confident than in face-to-face or letter communication: "more input is offered and this input is more freely opinionated". ${ }^{6}$

- The on-line newspapers contain a large number of references and links to other authors, texts, sources of information. The ordinary printed newspapers contain only citations from other sources or authors that are introduced in a linear form. Through the links the readers may be connected to other information sources relevant to this or that article.

DON'T BOMB US....In the ever expanding blogosphere, the latest entry is a blog from several Al Jazeera staffers titled, appropriately, "Don't Bomb Us". Here are five things they would like you to know:

1. Al Jazeera was the first Arab station to ever broadcast interviews with Israeli officials.

2. Al Jazeera has never broadcast a beheading.

3. George W. Bush has received approximately 500 hours of airtime, while Bin Laden has received about 5 hours of airtime.

4. Over 50 million people across the world watch Al Jazeera.

5. The Al Jazeera websites are (Arabic) and (English). AlJazeera.com, AlJazeerah.info and all other variations have nothing to do with us...

- The advertisement introduced in electronic newspapers may immediately connect the reader (the customer) with the advertised product company in case the reader 
wishes to purchase the product via the Internet. The advertisements in printed publications are devoid of this advantage, hence, the advertising and commercial opportunities of on-line newspapers are much broader. Thus, for example,

Let your body absorb more oxygen with better breathing. J26.99

- Virtual newspapers contain a number of technical advantages: automatic delivery system, unlimited capacity of archives, the absence of the notion of copies, the availability of searching services.

Summing up the above mentioned, we might say that an on-line newspaper as electronic mass medium plays a significant role in creating computer-mediated communication between people. The virtual discourse between the newspaper writers and readers is more direct and reader-oriented than in ordinary printed newspapers, and the readers are becoming not only the objects but also the subjects of such a discourse. The newspaper articles represent formal English with the accurate observance of grammar and punctuation rules. However, the readers' comments represent rather informal than formal speech, full of informal lexis and idioms. The advertisements in online newspapers are also interactive, as they can link the readers to the advertised companies for buying various advertised products.

Ultimately, the virtual discourse of on-line newspapers is a non-linear, hypertextual phenomenon that represents a specific type of asynchronous and synchronous communication between the newspaper authors and readers (interactants).The information is transmitted not only from the newspaper to the readers but also vice versa. Hence, the virtual discourse of an on-line newspaper is a sort of a written interactive dialogue between the communicants where the language choice depends on the extralinguistic motivation, genre peculiarities and electronic medium features.

\section{References:}

1. Chesher Chris. Construction of the Discourse of Virtual reality, 1984-1992.// Cultronix - Issue One - Fall 1994. (http://eserver.org/cultronix/01/), 1994, p.3.

2. Bolter Jay David. Writing Space: The Computer, Hypertext, and the History of Writing. Hillsdale, NJ: Erlbaum, 1991. (http://www.cas.usf.edu/english/walker/papers/\#bolter)

3. Munslow Alun. Discourse and Culture: The creation of America 1870-1920. 1992, p.2.

4. Nosik Anton. Gazeta.ru: Why do we need it? InterNet magazine, \#14(http:www.gazeta.ru)

5. Zasurskij Ya. N. The Information Society, the Internet and the New Means of Mass Media. // Information Society, 2001, Vol. 2. p.26.

6. Sellin Rob; Winters, Elaine. Cross-Cultural Communication. Section 7: Internationalization of Documentation. Internet Communication. (http://www.bena.com/ewinters/sect7.html), 1999. 


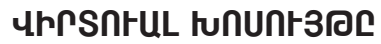

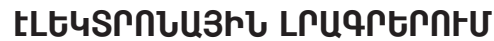

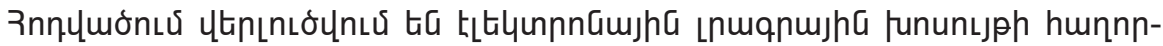

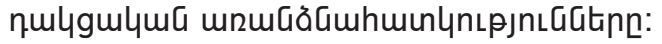

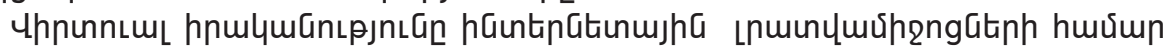

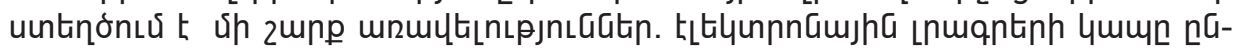

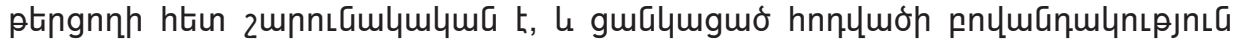

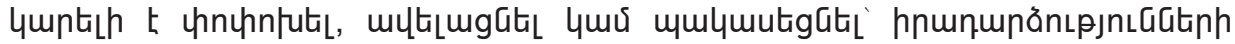

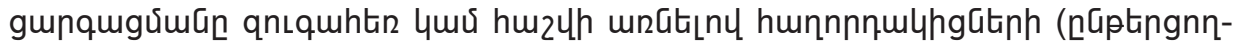

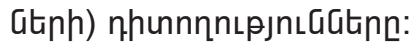

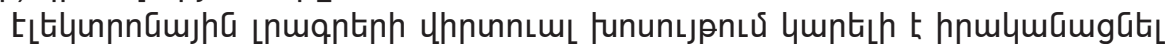

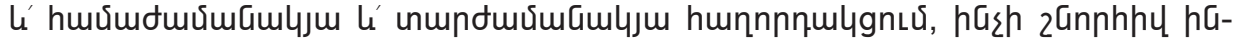

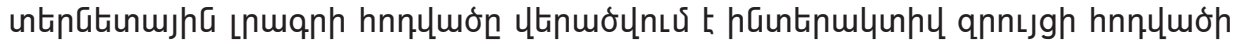

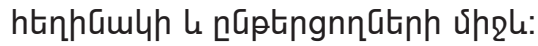

